\section{Serious complications of an obstructive upper airway infection in a young child}

\author{
SANDRA KRALIK・ IVAČICA ŠKARIĆ • DIANA BUTKOVIĆ • LILI MIKECIN •
} KARMEN KONDŽA • JASMINKA JAKOBOVIĆ
$\operatorname{SANDRA} \operatorname{KRALIK}(\bowtie) \cdot$ IVAČICA ŠKARIĆ • DIANA BUTKOVIĆ • LILI MIKECIN • KARMEN KONDŽA • JASMINKA JAKOBOVIĆ Department of anaesthesiology and intensive care Children's Hospital Zagreb, Klaićeva 16. 10000 Zagreb, Croatia Phone: 38514600224 Fax: 38514600169 E-mail: sakov@mef.hr

\begin{abstract}
A 15-month old boy was admitted to our intensive care unit (ICU) cyanotic, unresponsive, apneic, pulseless, with fixed, dilated pupils and a Glasgow Coma Score (GCS) of 3/15. Prompt cardiopulmonary resuscitation (CPR) was initiated and cardiac function was resumed after 10 minutes. The boy was intubated but could not be ventilated because of a thick, viscous secretion obstructing the trachea and causing total airway obstruction. Bronchoscopy revealed laryngotracheitis as the reason for airway obstruction. A computed tomography (CT) scan of the brain showed diffuse edema and ischemic brain injury, which were considered responsible for the boy's comatose situation. Clinical status remained unchanged for 11 days, after which the boy was transported to another hospital. In children presenting with upper airway obstructing syndromes, not responding to therapy, the diagnosis of bacterial tracheitis should be considered and the child should be monitored in a pediatric intensive care unit.
\end{abstract}

Key words: children, respiratory infection, airway obstruction, bacterial tracheitis

\section{Introduction}

Acute respiratory tract infections affecting infants and young children are in origin either viral (parainfluenza type I, RSV, influenza A and B, adeno-, entero-, rhino- or measles viruses) or bacterial (Haemophillus influenzae, Staphylococcus aureus, Streptococcus pneumoniae or Mycoplasma pneumoniae). (1) They are characterized by a sudden onset of croup syndrome, high fever, malaise, somnolence, leukocytosis, coughing, and respiratory insufficiency. (2) Management of these conditions is significantly different and accurate diagnosis is crucial. Although rare, obstructive laryngotracheobronchitis, as well as bacterial epiglottitis, still occurs, causing an acute and sometimes fatal illness of the upper and lower respiratory tract (3) and suggesting a change in epidemiology data. $(4,5)$ They are characterized by an upper or lower airway obstruction with mucous swelling and purulent, viscous sputum, and present with fever, dyspnoea, hypoxemia, cough and respiratory insufficiency. (6) The obstruction is most pronounced in the epiglottic and subglottic region causing inspiratory stridor and respiratory distress. (7) The disease lasts 10 to 15 days, and still has a rather high fatality rate.

\section{Case presentation}

A 15-month old boy had a dry cough and high fever on the day before admission to hospital. He was born from a mother's first twin pregnancy, IVF (in vitro fertilisation), in the $36^{\text {th }}$ week of gestation when a CS (Caesarean section) was performed. Otherwise healthy, he had been vaccinated according to schedule, without complications, but had not been vaccinated against $\mathrm{HiB}$ (Haemophillus influenza type B). At the same time, his twin sister was hospitalized for her febrile state.
Twelve hours before arriving at the hospital the child was febrile so the child's mother gave a paracetamol suppository. Ten hours before hospitalization the boy was still febrile (up to $40,7^{\circ} \mathrm{C}$ ) and started vomiting. Two hours later he was still febrile $\left(39,4^{\circ} \mathrm{C}\right)$. He developed dyspnoea and a cough and was given a second paracetamol suppository.

During the last four hours, before arriving at the hospital, he was fighting for air but was still conscious. He then became apnoeic

30 minutes before admission he developed convulsions lasting for 5 seconds, became unconscious, with dilated pupils and a fixed gaze. He was given $4 \mathrm{mg}$ of intramuscular dexamethasone and 20 mcg of subcutaneous epinephrine by an on-call paediatrician. The parents contacted the doctor being closest to their place of stay. No supplemental oxygen was administered and this was the only medical assistance given to the child thus far. Intensive care unit (ICU) setting: an ini- 
tial examination revealed a pulseless, cyanotic, apnoeic boy, unreactive with dilated fixed pupilsand a Glasgow Coma Score (GCS) of 3/15. Immediate cardiopulmonary resuscitation (CPR) was started with $100 \%$ oxygen. The upper respiratory tract was aspirated and the trachea was intubated but could not be ventilated because the endotracheal tube (ET) was obstructed with purulent secretions. The tube was removed and a lot of pus was visible in its lumen. The trachea was re-intubated, but the boy

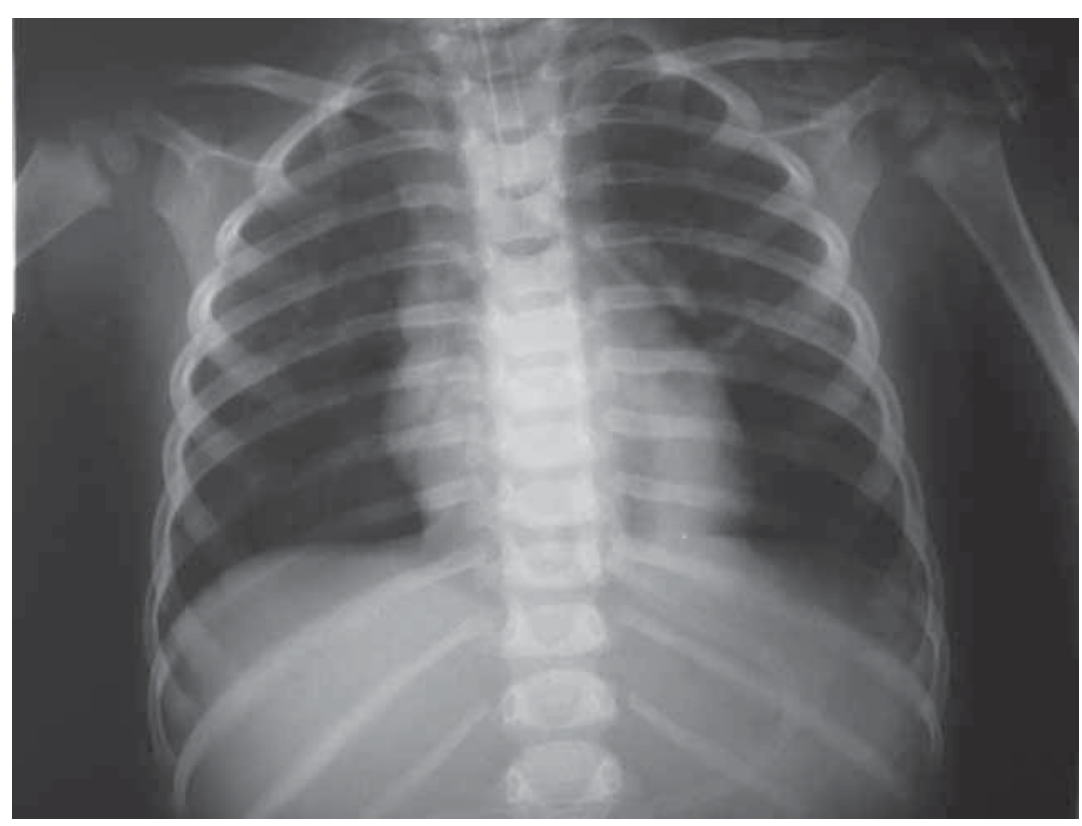

Figure 1. Chest X-ray.

still could not be ventilated. Withdrawal of the tube was attempted with simultaneous suctioning and a lot of pus was aspirated from the boy's trachea. The patient was successfully intubated after a third attempt. Positive pressure ventilation was accomplished with a respiratory rate of 40 breaths per minute, fraction of inspiratory $\mathrm{O}_{2}\left(\mathrm{FiO}_{2}\right) 1.0$ and a positive inspiratory pressure of $25 \mathrm{cmH}_{2} \mathrm{O}$. Ten minutes later cardiac function returned with a heart rate of 80 beats per minute showing normal electrocardiographic (ECG) findings. During CPR the boy developed generalized tonic-clonic convulsions for which thiopental 30mg was given. Continuous thiopental $5 \mathrm{mg} / \mathrm{kg} / \mathrm{h}$ was introduced for sedation.

An urgent bronchoscopy revealed normal structure and appearance of the epiglottis, trachea and larynx covered with purulent, viscous secretions and pus; tracheal mucosa being vulnerable, oedematous and hemorrhagic, indicating tracheitis as a cause of the airway obstruction. Pulmonary basal hyperinflation with segmental atelectasis of the upper left lobe became evident on the X-ray (figure 1). Mechanical ventilation was maintained using several controlled and assisted modes in order to wean which was accomplished on the $9^{\text {th }}$ day.

Urine, blood and liquor specimens were collected for testing. Nasopharyngeal and throat smears were also taken for culturing. Initial laboratory tests showed a white cell count of $25 \times 10^{9} / \mathrm{l}$, CRP (C-reactive protein) of $30 \mathrm{mg} / \mathrm{l}$ and arterial lactate of $6.5 \mathrm{mmol} / \mathrm{l}$, the rest being within normal limits. Initial arterial blood gases revealed no acidosis, contrary to our expectations.

After re-establishing vital functions, the boy suffered seizures, so a barbiturate coma was induced using thiopental for two days, as described above. Afterwards, seizures were controlled with phenobarbital $50 \mathrm{mg}$ and midazolam $2 \mathrm{mg}$. Next day a brain computed tomography (CT) scan (figure 2) was performed showing diffuse oedema and ischemic lesions, combined with an unclear border between the white and grey matter, thus confirming the etiology of the boy's comatose state. An EEG showed diffuse, slow activity, without any cortical activity in part. Oedema of the papillae was evident on fundoscopic examination.

Since a bacterial respiratory tract infection, as the initial cause of the airway obstruction, was suspected antibiotic treatment was commenced with ceftriaxone 100mg/day, however all microbiology samples were negative, later on. Four days after the incident, a microbiologically positive acute laryngotracheitis, (Influenza A and Haemophillus influenza B) was diagnosed in the boy's twin sister.

Eleven days after admission, and still in a coma, the patient was transported to the Paediatric ICU in Vienna, because the parents were Austrian residents. At the time of transport the boy was subfebrile, triparetic (moving only his left arm), unreactive, with spontaneous eye opening and dilated pupils reacting sluggishly to light. Still intubated, dyspneic but breathing spontaneously on CPAP (continious positive airway pressure) with pressure support of $8 \mathrm{cmH}_{2} \mathrm{O}$, the boy was producing a lot of secretion.

\section{Discussion}

Taking into consideration the epidemiology of childhood infections, the immunization profile of the patient (the boy had not been vaccinated against $\mathrm{H}$. influenza type B), as well as the positive microbiology smears in the boy's twin sister, we assume that the etiology of the tracheitis causing upper airway obstruction in our patient was $\mathrm{H}$. influenza type $\mathrm{B}(\mathrm{HiB})$. Bacterial infection of the trachea resulted in inflammation, swelling, purulent secretions and life-threatening narrowing of the upper airways, causing asphyxia and cardio-respiratory arrest. As a result of an evolving medical practice, the epidemiology of potentially lifethreatening airway infections is changing. Bacterial tracheitis is an uncommon airway infection that can cause lifethreatening airway obstruction, which can present with symptoms resembling 


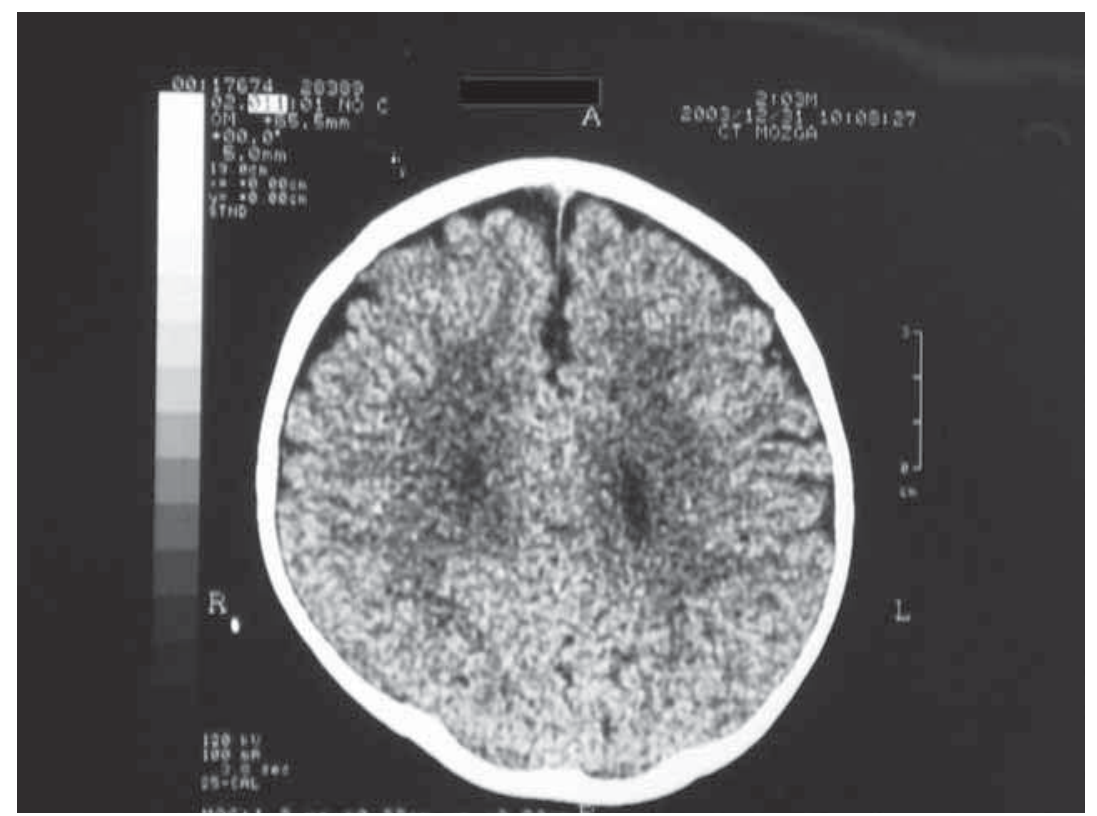

Figure 2. CT brain scan.

viral laryngotracheobronchitis or epiglottitis. The incidence of bacterial tracheitis, which has become now more common than epiglottitis, is estimated to be 8 per million children aged $0-5$ years. (8) Children may present with a brief period of rhinorrhea, fever, cough, sore throat and hoarse voice. Typically, they deteriorate rapidly, with respiratory distress, airway compromise and toxic appearance. (5) That was the case with our patient as well, who had fever and evolving respiratory tract symptoms only the last eight hours before he of early childhood $\mathrm{H}$. influenza type B typical epiglottitis, while routine use of corticosteroids for viral croup (even for mild cases) has dramatically changed the morbidity of these entities. Vaccine failure, as well as low HiB antibody titre, has been reported, emphasizing the importance of considering acute epiglottitis in the differential diagnosis of the child presenting with acute upper airway obstruction. (3) On the other hand, bacterial tracheitis is 3 times more likely to cause respiratory failure than viral croup and epiglottitis combined. (5)

The significance of recognizing and treating a child with an acute respiratory tract obstruction could not have been emphasized well, than in our case. We should always keep in mind how "little" is needed to completely obstruct a small child's airway. If one assumes that a trachea of a 15-month old child is around $5 \mathrm{~cm}$ long and has an internal diameter of $12-13 \mathrm{~mm}$, this makes a total volume of only 5.5 to $6.6 \mathrm{~mL}$. It is not that hard to imagine how little is needed for any secretion to fill that space.

In conclusion, although immunization against $\mathrm{H}$. influenza type $B$ has lowered the incidence of epiglottitis, the problem of bacterial tracheitis still exists. It is essential to monitor and reassess any upper airway obstructive syndrome that is not improving with appropriate therapy and these children should receive treatment in a paediatric intensive care unit.

\section{REFERENCES}

1. Mardešić D. Respiratory tract diseases. In: Mardešić D, editor. Paediatrics. 6th ed. Zagreb(ZG): Školska knjiga; 2000. p. 763-813.

2. Infectious diseases. In: Beers MH, Berkow R, Bogin RM, Fletcher AJ, editors. The Merck Manual of Diagnosis and Therapy. 17th ed. Whitehouse Station N.J.: Merck \& Co; 1999. p. 1085-1339

3. McEvan J, Giridharan W, Clarke RW, Shears P. Paediatric acute epiglottitis: not a disappearing entity. Int J Pediatr Otorhinolaryngol 2003:67(4):317-21

4. Wood N, Menzies R, Mclntyre P. Epiglottitis in Sydney before and after the introduction of vaccination against Haemophillus influenzae type b disease. Intern Med J 2005;35(9):530-5.

5. Hopkins A, Lahiri T, Salerno R, Heath B. Changing epidemiology of life-threatening upper airway infections: the re-emergence of bacterial tracheitis. Paediatrics 2006;118(4):1418-21.

6. Sobol SE, Zapata S. Epiglottitis and croup. Otolaryngol Clin North Am 2008;41(3):551-66.

7. Devlin B, Golchin K, Adair R. Paediatric airway emergencies in Northern Ireland, 1990-2003. J Laryngol Otol 2007;121 (7):659-63

8. Oymar K. Bacterial tracheitis in children. Tidsskr Nor Laegeforen 2000;120(12):1417-9.

9. Rajan S, Emery KC, Sood SK. Bacterial tracheitis. [Online]. 2006 Oct 19 [citied 2008 Sept 19]; Available from: URL:http://emdicine.com/ ped/byname/bacterial-tracheitis.htm

10. Donnelly BW, McMillan JA, Weiner LB. Bacterial tracheitis: report of eight new cases and review. Rev Infect Dis 1990;12:729-35.

11. Britto J, Habibi P, Walters S, Levin M, Nadel S. Systemic complication associated with bacterial tracheitis. Arch Dis Child 1996;74:249-50.

12. Labourel H, Emeiraud G, Ladwig M, Koch FX, Menthonnex E. Out-of-hospital cardiac arrest in children with bacterial tracheitis. Arch Pediatr 2008;15(3):279-82 